\title{
Are potassium levels in children with hemolytic uremic syndrome predictive of outcome?*
}

\author{
Miguel M. Glatstein ${ }^{1,2 \#}$, Vala Snehal ${ }^{3}$, Syed Amir Ahmad ${ }^{4,5}$, Dennis Scolnik ${ }^{4,6}$ \\ ${ }^{1}$ Division of Pediatric Emergency Medicine, Department of Pediatrics, Dana’s Children Hospital, University of Tel Aviv, Tel Aviv, \\ Israel \\ ${ }^{2}$ Division of Clinical Pharmacology and Toxicology, Ichilov Hospital, University of Tel Aviv, Tel Aviv, Israel \\ ${ }^{3}$ Division of Neonatal and Pediatric Emergency Medicine, Synergy Neonatal and Pediatric Hospital, Ahmadabad, India \\ ${ }^{4}$ Division of Pediatric Emergency Medicine, Department of Pediatrics, The Hospital for Sick Children, University of Toronto, \\ Toronto, Canada \\ ${ }^{5}$ Department of Emergency Medicine, King Khalid University Hospital, King Saud University, Riyadh, Saudi Arabia \\ ${ }^{6}$ Division of Clinical Pharmacology and Toxicology, Department of Pediatrics, The Hospital for Sick Children, University of Toronto, \\ Canada

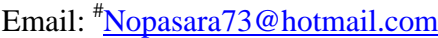

Received 21 June 2012; revised 17 September 2012; accepted 3 October 2012

\begin{abstract}
Objective: To ascertain the role of serum potassium levels in predicting clinical outcomes in diarrhea-associated hemolytic uremic syndrome (HUS D+). Methods: We reviewed clinical and laboratory data from HUS D+ patients at our tertiary care institution from 2001 to 2008. Serum potassium concentration at presentation and during the acute phase of acute renal failure were recorded and related to laboratory parameters and clinical outcomes. Results: 15 HUS D+ cases were identified. $E$. coli $0157: \mathrm{H7}$ was found in 9/15 cases $(\mathbf{7 0 \%})$. Potassium levels were not predictive of clinical outcomes. Normal serum potassium levels were found in the majority of patients. Potassium levels $<3.6 \mathrm{mmol} / \mathrm{L}$ were evident at presentation in $3 / 15$ patients $(23 \%)$, and no patient manifested hyperkalemia even when creatinine levels were concurrently increase. Conclusions: This study suggests the presence of vigorous compensatory mechanisms in the homoestasis of serum potassium levels during HUS D+ disease since neither the increase stool volumes associated with diarrhea nor the presence of renal failure resulted in clinically significant changes in serum potassium levels.
\end{abstract}

Keywords: Diarrhea; Hemolytic Uremic Syndrome; Hypokalemia; Potassium Metabolism; Acute Renal Failure

*Conflict of Interest: The Authors do not have a financial relationship with any organization that sponsored this research.

\#Corresponding author.

\section{BACKGROUND}

Hemolytic-Uremic Syndrome (HUS) is defined by the triad of microangiopathic hemolytic anemia, thrombocytopenia and acute renal failure. Annual incidence approaches 1 case per 100,000 children with peak prevalence in the summer [1], and most cases occur in children under five years of age [2]. HUS is a heterogeneous group of similar entities characterized by a variety of prothrombotic host abnormalities [3], with variable clinical expression and severity [4,5]. It is often associated with diarrhea (HUS D+) caused by gastrointestinal infections with Shiga toxin-producing E. coli, which likely produce their effect through the systemic spread of bacterial derived toxins $[6,7]$. The disease has been linked to consumption of hamburger meat contaminated with toxin-producing E. coli 0157:H7 [1,8].

HUS is the most frequent cause of non-pre-renal acute renal failure in pediatrics. HUS D+ accounts for $>80 \%$ of pediatric cases. The majority of children with HUS D+ develop some degree of renal insufficiency, and approximately two thirds of children with HUS will require dialysis therapy, while about one third will have milder renal involvement and no need for dialysis. Electrolyte abnormalities encountered in HUS D+ include hyponatremia and both hypo- and hyper-kalemia [9] although no large studies have examined changes in potassium levels in children with HUS D+. We therefore sought to examine potassium levels in patients with HUS D+ at our institution in an attempt to do understand the pathophysiology of potassium metabolism in HUS D+. 


\section{METHODS}

A retrospective chart review was performed of all patients aged $<16$ years with HUS D+ seen from April 1st 2001-November 2008. Twenty five patients had HUS, and the medical records of the 15 patients who were HUS D+ were reviewed. Potassium levels at presentation and during hospitalization were recorded. Serum potassium concentrations of $>5 \mathrm{mmol} / \mathrm{l}$ were used to define hyperkalemia and $<3.6 \mathrm{mmol} / \mathrm{l}$ to define hypokalemia. Serum sodium levels $<135 \mathrm{mmol} / \mathrm{l}$ being defined as hyponatremia. No medication that could affect potassium homeostasis was used by any patient prior to presentation.

Clinical outcomes were judged by the extent and duration of renal dysfunction, the duration of dialysis, hypertension, and the length of hospital stay, modeled after the classification of Trompeter, et al. [10]. Adapting these criteria, patients were classified into one of three categories:

Group 1: Patients who had a self-limited clinical course with mild thrombocytopenia and mildly decreased renal function, not requiring dialysis. The hospital stay was typically less than seven days with normal renal function and only minor abnormalities in urinary sediment present at discharge.

Group 2: Patients with more severe and prolonged thrombocytopenia with renal failure requiring 1 - 21 days of peritoneal dialysis. No hypertension developed, and pa- tients were discharged within 2 - 3 weeks. Mild proteinuria with otherwise normal renal function was present at discharge.

Group 3: Patients with marked and prolonged thrombocytopenia with renal failure, requiring permanent dialysis.

\section{RESULTS}

The study group consisted of six (40\%) females and nine (60\%) males with ages ranging from 2.5 - 15 (median 6.6) years. Utilizing the Trompeter classification [10], 9 (60\%) of the children had a very good outcome (Group 1 ) and the other $6(40 \%)$ recovered fully after a more prolonged clinical course (Group 2). No patient developed end stage renal disease (Group 3)—See Table 1.

As per definition diarrhea was recorded in all 15 patients and bloody stools were present in 13 (93\%). The diagnostic triad associated with HUS D+ occurred in 13 patients (93\%); in two patients the platelet counts remained normal throughout the illness (see Table 1). Stool cultures showed evidence of a bacterial pathogen in 10 cases (76\%), E. coli 0157:H7 accounted for nine of these. Non-0157 E. coli, Salmonella non-typhi and Toro-virus, were each found in the stool of one patient. The median duration of hospital stay was 14 days (range 3 - 40 days) and two (14\%) patients were admitted to the pediatric in-

Table 1. Children with HUS D+.

\begin{tabular}{|c|c|c|c|c|c|c|c|c|c|c|c|}
\hline Patient \# & $\begin{array}{c}\text { Age in } \\
\text { Years }\end{array}$ & $\begin{array}{c}\text { Creatinine in } \\
\mathrm{mmol} / \mathrm{L}\end{array}$ & $\begin{array}{c}\text { Initial } \\
\text { Platelet } \\
\text { Count } \times 10^{9}\end{array}$ & Sex & $\begin{array}{l}\text { Potassium } \\
\text { on Admission } \\
\text { in } \mathbf{m m o l} / \mathrm{L}\end{array}$ & Dialysis & $\begin{array}{c}\text { Received } \\
\text { Blood }\end{array}$ & $\begin{array}{c}\text { Trompeter } \\
\text { Grade }\end{array}$ & Agent & $\begin{array}{l}\text { Sodium on } \\
\text { Admission } \\
\text { in } \mathrm{mmol} / \mathrm{L}\end{array}$ & $\begin{array}{c}\text { Bicarbonate on } \\
\text { Admission in } \\
\text { mmol/L }\end{array}$ \\
\hline 1 & 2 & 85 & 283 & M & 4.4 & No & Yes & 1 & No & 130 & 19 \\
\hline 2 & 9 & 429 & 57 & M & 5 & Yes & Yes & 2 & No & 135 & 18 \\
\hline 3 & 6 & 85 & 68 & $\mathrm{M}$ & 4.3 & No & Yes & 1 & E. coli & 140 & 19 \\
\hline 4 & 13 & 340 & 58 & M & 4 & No & No & 2 & Torovirus & 134 & 22 \\
\hline 5 & 2 & 107 & 341 & M & 5 & Yes & Yes & 2 & E. coli & 132 & 20 \\
\hline 6 & 10 & 140 & 40 & M & 4.2 & No & Yes & 1 & E. coli & 138 & 24 \\
\hline 7 & 13 & 317 & 37 & M & 4 & No & Yes & 2 & E. coli & 133 & 22 \\
\hline 8 & 4 & 83 & 79 & M & 3.2 & No & Yes & 1 & Salmonella & 140 & 23 \\
\hline 9 & 2.5 & 230 & 44 & $\mathrm{~F}$ & 3.3 & Yes & Yes & 1 & E. coli & 133 & 18 \\
\hline 10 & 3.5 & 449 & 93 & $\mathrm{~F}$ & 4 & No & Yes & 1 & E. coli & 144 & 23 \\
\hline 11 & 4.5 & 135 & 23 & F & 3.8 & Yes & Yes & 2 & E. coli & 134 & 12 \\
\hline 12 & 4 & 159 & 45 & M & 3.7 & No & Yes & 1 & E. coli & 133 & 28 \\
\hline 13 & 6 & 217 & 72 & F & 3.4 & Yes & Yes & 2 & E. coli & 129 & 16 \\
\hline 14 & 14 & 207 & 42 & $\mathrm{~F}$ & 4.2 & No & Yes & 1 & No & 138 & 22 \\
\hline 15 & 4 & 102 & 25 & $\mathrm{~F}$ & 4.1 & No & Yes & 1 & No & 137 & 14 \\
\hline
\end{tabular}


tensive care unit. Arterial hypertension was observed in two patients $(14 \%)$ and neurological defects in three (21\%). Renal replacement therapy was instituted in six (46\%) patients: five received peritoneal dialysis and one haemodialysis.

Hypokalemia was seen in three patients (21\%). No patient developed hyperkalemia, despite acute renal failure with mean serum creatinine levels of $202 \mathrm{mmol} / \mathrm{l}$. Hyponatremia was seen in seven patients (50\%), but was not severe (lowest value $129 \mathrm{mmol} / \mathrm{L}$ ), nor was there any association with clinical outcomes.

\section{DISCUSSION}

At presentation, serum potassium levels in our patients were low or normal, and no patients manifested hyperkalemia. Potassium levels, even prior to dialysis, were not predictive of clinical outcomes, which were uniformly favorable with no mortality.

Acute renal failure in HUS generally manifests as hypertension, oliguria, metabolic acidosis and hyperkalemia and management consists of appropriate fluid and electrolyte management, antihypertensive therapy, and the initiation of renal replacement therapy when appropriate [11]. In vitro studies have found that there may be local activation of the renin-angiotensin system during the course of HUS, contributing to the thrombotic microangiopathy which is a significant modulator of severity disease in HUS [12]. Renin-angiotensin system activation then contributes to hypertension. Diarrhea in children can cause electrolytes abnormalities such as hyponatremia, hypokalemia and metabolic acidosis with normal anion gap [13]. The concentration of potassium in normal stool is $80-90 \mathrm{mmol} / \mathrm{l}$, but because of the low volume of water in normal stool, only about $10 \mathrm{mmol}$ of potassium is normally lost each day [14]. In diarrheal states, although the potassium concentration in stool decreases, large quantities of potassium can nevertheless be lost as the volume of stool increases [15]. Thus any condition, such as infectious diarrhea, that increases stool volume can result in clinically significant potassium depletion and hypokalemia. Profuse watery diarrhea is usually not present at the time of presentation in patients with HUS since diarrhea usually precedes the onset of HUS rather than coinciding with it [16]. This may explain the normokalemia found in the majority of our patients. In most of our HUS D+ patient population any decreases in serum potassium appear to have been counter balanced by the elevations in serum potassium that occur in renal failure.

The results of this preliminary, hypothesis-generating pilot study suggest that there appears to be a balance between diarrheal losses of potassium and retention of potassium associated with acute renal failure in patients with HUS D+ and that neither initial levels of potassium nor those found during the course of hospitalization are predictive of clinical outcomes. The number of patients in our study is low, limiting the strength of conclusions that can be drawn regarding potassium levels and disease outcomes in HUS D+ disease. Measurement of blood pressure, blood $\mathrm{pH}$, renin and aldosterone levels, stool and urine volumes and the concentration of potassium in each, would have helped clarify potassium homeostasis in our patients. Metabolic acidosis with a random urine potassium-creatinine ratio less than 1.5 may suggest excessive gastrointestinal losses due to diarrhea, or a shift of potassium into cells.

\section{REFERENCES}

[1] Brandt, J.R., Fouser, L.S., Watkins, S.L., Zelikovic, I., Tarr, P.I., Nazar-Stewart, V. and Avner, E.D. (1994) Escherichia coli 0157:H7-associated hemolytic uremic syndrome after ingestion of contaminated hamburgers. The Journal of Pediatrics, 125, 519-526. doi:10.1016/S0022-3476(94)70002-8

[2] Loirat, C. (2001) Post-diarrhea hemolytic uremic syndrome. Archives of Pediatrics \& Adolescent Medicine, 8 , 776-784. doi:10.1016/S0929-693X(01)80196-2

[3] Ake, J.A., Jelacic, S., Ciol, M.A., Watkins, S.L., Murray, K.F., Christie, D.L., Klein, E.J. and Tarr, P.I. (2005) Relative nephroprotection during Escherichia coli 0157:H7 infections: Association with intravenous volume expansion. The Journal of Pediatrics, 115, 673-680. doi:10.1542/peds.2004-2236

[4] Copelovich, L. and Kaplan, B.S. (2008) The thrombotic microangiopathies. Pediatric Nephrology, 23, 1761-1767. doi:10.1007/s00467-007-0616-x

[5] Loirat, C., Sonsino, E., Varga-Mareno, A., Pillion, G., Mercier, J.C., Beaufils, F. and Mathieu, H. (1984) Hemolytic uremic syndrome: An analysis of the natural history and prognostic features. Acta Paediatrica Scandinavica, 73, 505-514. doi:10.1111/j.1651-2227.1984.tb09962.x

[6] Gavin, P.J., Peterson, L.R. and Pasquariello, A.C. (2004) Evaluation of performance and potential clinical impact of prospect Shiga toxin Escherichia coli microplate assay for detection of Shiga toxin producing $E$. coli in stool samples. Journal of Clinical Microbiology, 42, 1652-1656. doi:10.1128/JCM.42.4.1652-1656.2004

[7] Kehl, K.S., Havens, P., Behnke, C.E. and Acheson, D.W. (1997) Evaluation of the premier EHEC assay for detection of Shiga toxin-producing Escherichia coli. Journal of Clinical Microbiology, 35, 2051-2054.

[8] Griffen, P. and Tauxe, R. (1991) The epidemiology of infections caused by Escherichia coli 0157:H7, other enterohemorrhagic E. coli and the associated hemolytic uremic syndrome. Epidemiologic Reviews, 13, 60-98.

[9] Rosenfield, A.T. and Siegel, N.K. (1981) Renal parenchymal disease: Histopathologicsonographic correlation. American Journal of Roentgenology, 137, 793-798.

[10] Trompeter, R.S., Schwartz, R., Chantler, C., Dillon, M.J., 
Haycock, G.B., Kay, R. and Barratt, T.M. (1983) Haemolytic uremic syndrome: An analysis of prognostic feature. Archives of Disease in Childhood, 58, 101-105. doi:10.1136/adc.58.2.101

[11] Scheiring, J., Rosales, A. and Zimmerhackl, L.B. (2010) Clinical practice. Today's understanding of the haemolytic uraemic syndrome. European Journal of Pediatrics, 169, 7-13. doi:10.1007/s00431-009-1039-4

[12] Nestoridi, E., Kushak, R.I., Tsukurov, O., Grabowski, E.F. and Ingelfinger, J.R. (2008) Role of the renin angiotensin system in TNF-alpha and Shiga-toxin-induced tissue factor expression. Pediatric Nephrology, 23, 221-231. doi:10.1007/s00467-007-0636-6

[13] Shah, G.S., Das, B.K., Kumar, S., Singh, M.K. and Bhan- dari, G.P. (2007) Acid base and electrolyte disturbance in diarrhoea. Kathmandu University Medical Journal, 5, 6062.

[14] Gennari, F.J. (2002) Disorders of potassium homeostasis. Hypokalemia and hyperkalemia. Critical Care Clinics, 18, 273-288. doi:10.1016/S0749-0704(01)00009-4

[15] Mandal, A.K. (1997) Hypokalemia and hyperkalemia. Medical Clinics of North America, 81, 611-639. doi:10.1016/S0025-7125(05)70536-8

[16] Glatstein, M., Miller, E., Garcia-Bournissen, F. and Scolnik, D. (2010) Timing and utility of ultrasound in diarrheaassociated hemolytic uremic syndrome: 7-year experience of a large tertiary care hospital. Clinical Pediatrics, 49, 418-421. doi:10.1177/0009922809342582 